\title{
Médaille d'argent du CNRS pour Cathy Clerbaux
}

Le CNRS a attribué la médaille d'argent à la chercheuse Cathy Clerbaux, du Laboratoire atmosphères et observations spatiales de l'IPSL, pour ses travaux sur le sondage infrarouge atmosphérique et l'exploitation des données de l'instrument Iasi. Avec son équipe, Cathy conçoit et met au point des algorithmes de traitement qui permettent de mesurer les propriétés chimiques mais aussi physiques de l'atmosphère et de la surface, à partir des spectres infrarouges mesurés par satellite. Cathy Clerbaux a démontré le potentiel des sondeurs infrarouges pour surveiller les pics de pollution, les grands feux de biomasse, les panaches de cendres volcaniques, les tempêtes de sable ou encore les émissions d'ammoniac associées à l'utilisation d'engrais par l'agriculture. Ses travaux trouvent des applications aussi bien à Eumetsat que dans le projet Copernicus de surveillance de l'environnement coordonné par le Centre européen pour les prévisions météorologiques à moyen terme. Son dernier projet de recherche vise à mieux comprendre et quantifier la variabilité naturelle et le changement du climat à partir de la longue série temporelle de données hyperspectrales acquises par les missions successives de Iasi (et dans le futur par celles de Iasi-NG). La revue lui présente toutes ses félicitations pour ce nouveau prix.
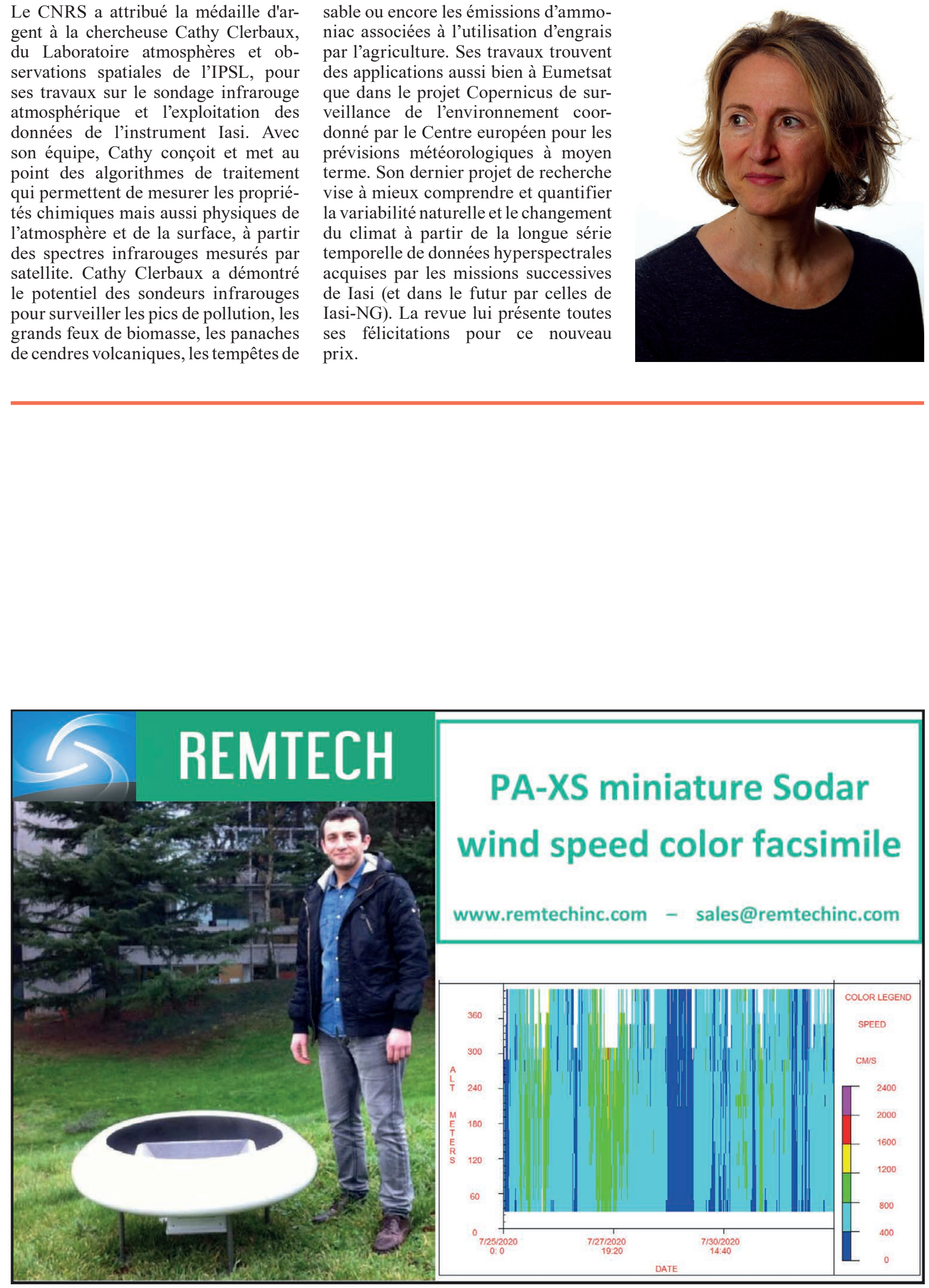


\title{
M MÉTÉORAGE
}

\section{PREVENTION \& MITIGATION DU RISQUE FOUDRE} pour sécuriser les biens etles personnes

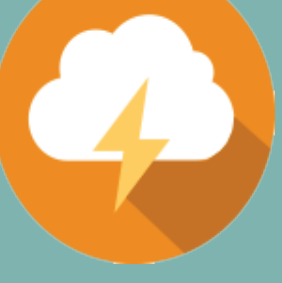

\author{
La mitigation, c'est quoi ? \\ Employé par l'ensemble de la communauté \\ internationale au sujet de la prévention des risques \\ naturels, le terme de Mitigation désigne «l'action qui \\ conduit à réduire les dommages sur les enjeux pour \\ les rendre plus supportables par la société.» \\ (source georisques.gour)
}

Spécialiste des orages et de la foudre en France et en

Europe, Météorage surveille le phénomène en permanence

et dispose de plus de 30 ans d'informations sur le sujet.

Cette connaissance approfondie du phénomène, associée au choix de la société de se doter d'un réseau de capteurs de détection de haute technologie, permet à Météorage de délivrer des services fiables et efficaces, adaptés aux besoins les plus spécifiques de l'ensemble de ses utilisateurs.

A l'origine de publications et de notes techniques, l'expertise de Météorage est internationalement reconnue sur les plans scientifiques et météorologiques.

Vous souhaitez en savoir plus sur notre activité?

Vous avez un projet d'étude scientifique ou technique concernant les orages ou leur détection? Contactez-nous ! 